\title{
National summit on physician employment finds no quick fixes for specialist job shortages
}

A national summit to tackle Canada's boom-bust cycle of physician employment has laid the groundwork for more coordinated workforce planning across the country, but yielded no immediate solutions.

The Feb. 18-19 summit in Ottawa, Ontario, which attracted more than 100 doctors, medical educators, students, researchers and representatives of government and medical organizations, concluded with a joint statement that "solutions must be developed to address the troubling number of unemployed and underemployed physicians countrywide." But the statement stopped short of providing concrete recommendations for change.

Instead, attendees committed to meet again in eight months to "exchange best practices and progress reports," and hash out a "draft action plan to streamline and coordinate efforts." In the meantime, the Royal College of Physicians and Surgeons of Canada will "coordinate and collect all relevant information regarding specialty-specific data on this issue."

The college's Director of Health Policy and External Relations Danielle Fréchette, who organized the summit, acknowledges that these commitments represent "baby steps" toward a panCanadian medical workforce plan. "People might be surprised that there was nothing a lot more concrete coming out of this," said Fréchette. But she adds that there are "no quick fixes" to the employment challenges facing physicians.

"I think history speaks for itself," she says. "In the "90s there were too many physicians, and very recently we had too few." Short-term solutions "just perpetuate the problems."

Employment issues are most pronounced for specialists and subspecialists, particularly those in surgical or resource-intensive disciplines, according to the Royal College. Some
$16 \%$ were unable to secure employment in 2011 and 2012, compared to $7.1 \%$ of all Canadians. Almost $22 \%$ of new graduates report staying employed by combining multiple locum or parttime positions, and $40 \%$ said they were not satisfied with the placements.

A dearth of information about the forces driving these trends has further complicated planning, explains Canadian Medical Association President Dr. Louis Hugo Francescutti. "We're still in the early stages of confirming whether these shortages or surpluses actually exist."

He cites the apparent surplus of orthopedic surgeons as an example. "It could be that we're training too many, or that they're not retiring when we expected they would as a result of the financial crisis, or that health care facilities are not providing new graduates the necessary resources to set up a practice."

Likely, "it's a combination of a number of elements," some of which may be difficult to predict or account for in medical workforce planning, says Francescutti.

The Royal College reports that approaches to allocating residency positions vary greatly across the country, "based on scant information about longer-term societal health needs and health care resources." Additionally, new medical graduates may move from the regions where they trained, creating further imbalances.

A centralized program to track supply and demand for health providers may be one solution, says Dr. Kathy Lawrence, president of the College of Family Physicians of Canada. But such a program would require federal leadership and coordination.

Fréchette says there will likely be "more systematic collection of data" in the months ahead. But any further comment on possible solutions is "premature." — Lauren Vogel, CMAJ

CMAJ 2014. DOI:10.1503/cmaj.109-4735 